August 17, 1999

\title{
A Note on Price and Quantity Competition in Differentiated Oligopolies
}

\author{
Jonas Häckner \\ Department of Economics, Stockholm University \\ S-106 91 Stockholm, Sweden
}

Phone: +46-8-163049 Fax: +46-8-159482 E-mail: jonas.hackner@ne.su.se

\begin{abstract}
In this note we show that the results developed in Singh and Vives (1984) are sensitive to the duopoly assumption (Rand Journal of Economics 15, 546-554). If there are more than two firms, prices may be higher under price competition than under quantity competition. This will be the case if quality differences are large and goods are complements. If goods are substitutes, high-quality firms may earn higher profits under price competition than under quantity competition. Hence, it is not evident which kind of competition is more efficient.
\end{abstract}

JEL Classification: D43, L13

Keywords: Product Differentiation, Oligopoly, Cournot, Bertrand 


\section{Introduction}

In a classic contribution to oligopoly theory Singh and Vives (1984) discuss the nature of competition in Bertrand and Cournot markets using the duopoly framework developed in Dixit (1979). The conclusions are strong and clear-cut. Cournot competition always yields higher prices and lower welfare compared to Bertrand competition. When goods are substitutes, firm profits are higher under Cournot competition while if goods are complements Bertrand competition is more profitable.

Considering the theoretical and practical importance of these results it seems important to test their robustness with respect to alternative market structures. We therefore extend the Dixit (1979) model to allow for an arbitrary number of firms. The discussion is limited to prices and profit levels since the welfare issue becomes too complex in a general setting.

For simplicity, we allow only for two dimensions of firm heterogeneity, vertical product differentiation and substitutability. ${ }^{1}$ Moreover, it is assumed that the marginal cost of production is equal across firms.

The Dixit (1979) model generalizes nicely despite the asymmetry that stems from vertical product differentiation. The linear demand structure ensures that firm demand depends only on the average quality of the competitors products while it is unaffected by changes in the exact distribution of product qualities across firms.

The duopoly results do not to generalize to the $n$-firm setting if quality differences are large. When goods are complements (and quality differences large) low-quality firms will charge prices that are higher under Bertrand competition than under Cournot competition. If goods are substitutes, high-quality firms may earn higher profits under Bertrand competition than under Cournot competition.

\section{The Model}

The utility function in Singh and Vives (1984) is of the following type

\footnotetext{
${ }^{1}$ When goods are substitutes, the degree of substitutability could be interpreted in terms of horizontal product differentiation.
} 


$$
U\left(q_{1}, q_{2}, I\right)=\alpha_{1} q_{1}+\alpha_{2} q_{2}-\frac{1}{2}\left(\beta_{1} q_{1}^{2}+\beta_{2} q_{2}^{2}+2 \gamma q_{1} q_{2}\right)+I
$$

For simplicity let us assume that $\beta_{1}=\beta_{2}=1$. Thus, utility is quadratic in the consumption of $q$ goods and linear in the consumption of other goods, $I$. The parameter $\gamma \in[-1,1]$ measures the substitutability between the products. If $\gamma=0$, each firm has monopolistic market power, while if $\gamma=1$, the products are perfect substitutes. A negative $\gamma$ implies that the goods are complementary. Finally, $\alpha_{i}$ measures quality in a vertical sense. Other things equal, an increase in $\alpha_{i}$ increases the marginal utility of consuming good $i$.

It is straightforward to generalize the utility function to allow for $n$ firms producing one product variety each.

$$
U(\boldsymbol{q}, I)=\sum_{i=1}^{n} q_{i} \alpha_{i}-\frac{1}{2}\left(\sum_{i=1}^{n} q_{i}^{2}+2 \gamma \sum_{i \neq j} q_{i} q_{j}\right)+I
$$

Consumers maximize utility subject to the budget constraint $\sum p_{i} q_{i}+I \leq m$, where $m$ denotes income and the price of the composite good is normalized to one. The first-order condition determining the optimal consumption of $\operatorname{good} k$ is

$$
\frac{\partial U}{\partial q_{k}}=\alpha_{k}-q_{k}-\gamma \sum_{j \neq k} q_{j}-p_{k}=0
$$

\section{Cournot Competition}

Firm $k$ 's inverse demand function can be solved for directly from expression 1.

$$
p_{k}\left(q_{k}, \boldsymbol{q}_{-i}\right)=\alpha_{k}-q_{k}-\gamma \sum_{j \neq k} q_{j}
$$

Firms set quantities to maximize profits, $\pi_{k}$, taking the other firms' quantities as given. If costs are normalized to zero, firm $k$ 's reaction function equals 


$$
q_{k}\left(\boldsymbol{q}_{-k}\right)=\frac{\alpha_{k}-\gamma \sum_{j \neq k} q_{j}}{2} .
$$

Summing over all firms and noting that

$$
\begin{aligned}
& \sum_{i=1}^{n} q_{i}=q_{k}+\sum_{j \neq k} q_{j} \\
& \sum_{i=1}^{n} \alpha_{i}=\alpha_{k}+\sum_{j \neq k} \alpha_{j}
\end{aligned}
$$

we can solve for demand and price in equilibrium

$$
q_{k}^{C}=p_{k}^{C}=\frac{\alpha_{k}[\gamma(n-2)+2]-\gamma \sum_{j \neq k} \alpha_{j}}{(2-\gamma)[\gamma(n-1)+2]}
$$

where superscript $C$ indicates Cournot equilibrium. Thus, firm $k$ 's equilibrium price and quantity depend on the average quality if its competitors products but are independent of the exact distribution of product qualities across firms.

\section{Bertrand Competition}

Summing over all firms, expression 1 can be written

$$
\sum_{i=1}^{n} \alpha_{i}-\sum_{i=1}^{n} q_{i}-\gamma(n-1) \sum_{i=1}^{n} q_{i}-\sum_{i=1}^{n} p_{i}=0
$$

Expressions 1, 2 and 3 then yield firm $k$ 's demand function.

$$
q_{k}\left(p_{k}, \boldsymbol{p}_{-k}\right)=\frac{\left(\alpha_{k}-p_{k}\right)[\gamma(n-2)+1]-\gamma \sum_{j \neq k}\left(\alpha_{j}-p_{j}\right)}{(1-\gamma)[\gamma(n-1)+1]} .
$$


Profit maximization (and zero costs) then implies the following reaction function

$$
p_{k}\left(\boldsymbol{p}_{-k}\right)=\frac{\alpha_{k}}{2}-\frac{\gamma \sum_{j \neq k}\left(\alpha_{j}-p_{j}\right)}{2[\gamma(n-2)+1]} .
$$

Summing this over all firms and using expressions 2 and 5 then yields the equilibrium prices and quantities for firm $k$

$$
\begin{gathered}
p_{k}^{B}=\frac{\alpha_{k}\left[\gamma^{2}\left(n^{2}-5 n+5\right)+3 \gamma(n-2)+2\right]-\gamma \sum_{j \neq k} \alpha_{j}[\gamma(n-2)+1]}{[\gamma(n-3)+2][\gamma(2 n-3)+2]} \\
q_{k}^{B}=\frac{\left[\alpha_{k}\left[\gamma^{2}\left(n^{2}-5 n+5\right)+3 \gamma(n-2)+2\right]-\gamma \sum_{j \neq k} \alpha_{j}[\gamma(n-2)+1]\right][\gamma(n-2)+1]}{(1-\gamma)[\gamma(n-3)+2][\gamma(n-1)+1][\gamma(2 n-3)+2]}
\end{gathered}
$$

where $B$ denotes Bertrand equilibrium. Again, firm $k$ 's equilibrium price and quantity depend on the average quality if its competitors products but are independent of the exact distribution.

\section{Bertrand and Cournot Equilibria}

The first proposition in Singh and Vives (1984) deals with the welfare implications of price and quantity competition. Cournot prices are found to be higher than Bertrand prices regardless of whether goods are complements or substitutes. This means that welfare is always higher under price competition. Moreover, Cournot profits are shown to be higher than Bertrand profits when goods are substitutes. If goods are complements, the opposite relation holds.

If we take the difference between the Cournot price and the Bertrand price of the generalized model we arrive at the following condition.

$$
\operatorname{sign}\left(p_{k}^{C}-p_{k}^{B}\right)=\operatorname{sign}\left(\alpha_{k}\left[\gamma^{2}\left(n^{2}-5 n+5\right)+4 \gamma(n-2)+4\right]-\gamma^{2}(n-2) \sum_{j \neq k} \alpha_{j}\right)
$$

Hence, unless $n=2$, the price differential consists of a positive and a negative term. The sign will 
be determined by the number of firms, the degree of horizonal differentiation and the quality distribution between firm $k$ and its competitors.

Proposition 1: Assume that $n>2$. i) When goods are substitutes, $p^{C}{ }_{k}>p^{B}{ }_{k}$. Hence, welfare is unambiguously higher when firms compete in prices. ii) When goods are complements, and quality differences are large, $p^{C}{ }_{k}<p^{B}{ }_{k}$ for low-quality firms.

Proof: First consider the case when goods are substitutes. Let $z_{k}$ be the ratio between the average quality offered by the rival firms, $\sum \alpha_{j} /(n-1)$, and the quality offered by firm $k, \alpha_{k}$. If $z_{k}<1$ firm $k$ produces a better product than the average rival and vice versa. Unless $z_{k}$ is small enough, firm $k$ will be driven out of the market in equilibrium. Specifically, under Bertrand competition $q^{B}{ }_{k}>0$ if

$$
z_{k}<\frac{\gamma^{2}\left(n^{2}-5 n+5\right)+3 \gamma(n-2)+2}{\gamma(n-1)(\gamma(n-2)+1)} \equiv z^{B}
$$

while the corresponding condition under Cournot competition is

$$
z_{k}<\frac{\gamma(n-2)+2}{\gamma(n-1)} \equiv z^{C}
$$

The second-order condition for an interior solution under Bertrand competition is c $>1 /(1-n)$. This ensures that $z^{B}<z^{C}$. Hence, it is not meaningful to talk about an $n$-firm market unless $z_{k}<z^{B}$.

The price differential is positive unless $z_{k}$ is large. Specifically, $p^{C}{ }_{k}-p^{B}{ }_{k}>0$ unless

$$
z_{k}>\frac{\gamma^{2}\left(n^{2}-5 n+5\right)+4 \gamma(n-2)+4}{\gamma^{2}(n-2)(n-1)} \equiv z *_{k} .
$$

It is straightforward to verify that there exists no $z_{k}$ that can satisfy the latter and the former inequalities simultaneously if $\gamma>0$. This proves the first part of the proposition.

Assume now that goods are complements and that the second-order conditions are satisfied, i.e. $\gamma \in[1 /(1-n), 0]$. Then, all firms face a positive demand in equilibrium regardless of the distribution of qualities. Consequently, $z_{k}>z_{k}^{*}$ is a sufficient condition for a negative price 
differential. It can be checked that $z^{*}{ }_{k}$ increases monotonically in $\gamma$. Moreover, $z^{*}{ }_{k}>0$ when $\gamma=1 /(1-n)$ and $z^{*}{ }_{k}$ approaches $+\infty$ as $\gamma$ approaches zero from below. Hence, for every $\gamma$ in the interval $[1 /(1-n), 0]$ there exists a threshold value $z^{*}{ }_{k}$ such that $z_{k}>z_{k}^{*}$ implies that $p_{k}^{C}<p_{k}^{B}$. Finally, $z_{k}^{*}$ decreases in $n$ and approaches $z_{k}^{*}=1$ as $\mathrm{n}$ approaches infinity. Hence, only firms producing qualities below average will charge higher prices under Bertrand competition than under Cournot competition.

A switch from Cournot to Bertrand competition will reduce the prices of high-quality products and increase equilibrium demand. If goods are complements, this will increase the demand for low-quality products which, in turn, may enable low-quality producers to raise their prices.

Proposition 2: i) When goods are complements, $\pi^{B}{ }_{k}>\pi^{C}$. ii) When goods are substitutes, and quality differences are small, $\pi^{C}{ }_{k}>\pi^{B}$. When quality differences are large it may be the case that $\pi^{B}{ }_{k}>\pi^{C}{ }_{k}$ for high-quality firms.

Proof: First define $\mathrm{G}\left(z_{k}\right)=\pi_{k}^{C} / \pi_{k}^{B}$ and let $z^{C}$ and $z^{B}$ be defined as in the proof of Proposition 1. If $\gamma=0$ then $\mathrm{G}\left(z_{k}\right)=1$. When goods are substitutes, $\mathrm{G}\left(z_{k}\right)$ increases in $z_{k}$. $\mathrm{G}(1)>1$ and $\mathrm{G}\left(z^{B}\right)=$ $+\infty$. Hence, only high-quality firms (i.e. firms with a low $z_{k}$ ) may have a profit ratio that is smaller than one. For instance, suppose that $\alpha_{j}=z_{k} \alpha_{k}, \forall j \neq k$. Then, let $z$ denote the lowest value of $z_{k}$ for which there is a positive demand for low-quality products in the Bertrand equilibrium. $G(\mathcal{A})<1$ as long as

$$
\gamma<\hat{\gamma}(n) \equiv \frac{\sqrt{n^{4}-2 n^{3}-5 n^{2}+14 n-7}+n^{2}-5 n+5}{2\left(n^{2}-3 n+2\right)} .
$$

$\gamma$ is increasing in $n$. $\hat{\gamma}(2)=0$ while $\gamma(\infty)=1$. Hence, for any market structure there exist a $\gamma$ small enough to make $G(\mathcal{A})<1$. This, in turn, implies that there exists some positive interval $[\mathcal{z}, \tilde{z}]$ such that $\mathrm{G}\left(z_{k}\right)<0$ if $z_{k} \in[\hat{z}, \tilde{z}]$.

When goods are complements $\mathrm{G}\left(z_{k}\right)$ decreases in $z_{k}$. Since $\mathrm{G}(0)<1$ the profit ratio is always smaller than one. $\square$

When quality differences are large, high-quality firms become insulated from competition from 
the low-quality segment. Therefore, price competition may not hurt firm profits more than quantity competition.

\section{Concluding Remarks}

We may conclude that the results in Singh and Vives (1984) are sensitive to the duopoly assumption. Although we have imposed more symmetry on the model, compared to the original formulation, the clear-cut dichotomy between Bertrand and Cournot competition is lost in the $n$ firm specification. Hence, it is not evident which type of competition is more efficient. 


\section{References}

Dixit, A., 1979, A Model of Duopoly Suggesting a Theory of Entry Barriers, Bell Journal of Economics 10, 20-32.

Singh, N., and X. Vives, 1984, Price and Quantity Competition in a Differentiated Duopoly, Rand Journal of Economics 15, 546-554. 